\title{
Identification of factors that impact recurrence in patients with borderline ovarian tumors
}

\author{
Xi Chen ${ }^{1}$, Chenyan Fang ${ }^{1}$, Tao Zhu ${ }^{1}$, Ping Zhang ${ }^{1}$, Aijun Yu ${ }^{1 *}$ and Shihua Wang ${ }^{2}$
}

\begin{abstract}
Background: The lack of consensus around best practices for management of borderline ovarian tumors (BOT) is, in part, to the lack of available data and of clarity in interpreting relationships among various factors that impact outcomes. The objective of this study was to identify clinicopathological factors that impact prognosis of patients with borderline ovarian tumors (BOT) and to address features of this disease with the objective of providing clarity in decision making around management of BOT.

Results: A total of 178 BOT patients were included in this study, with a median age of 43 years and a median follow-up time of 37 months. Thirty-two (18.0\%) recurrences and 5 (2.8\%) deaths were observed in this study group. Multivariate analysis showed that fertility-preserving surgery $(P=0.0223$ for bilateral cystectomy) and invasive implants $(P=0.0030)$ were significantly associated with worse PFS, whereas lymphadenectomy $(P=0.0129)$ was related to improved PFS. No factors were found to be associated with OS due to the limited number of deaths. In addition, patients with serous BOT more commonly had abnormal levels of CA125, while patients with mucinous BOT more commonly had abnormal levels of CEA. Patients with abnormal levels of CA125, or CA19-9, or HE4 had significantly larger tumor sizes.
\end{abstract}

Conclusions: Our study reveals the impact of certain types of fertility-preserving surgery, lymphadenectomy and invasive implants on PFS of BOT patients. Blood cancer markers may be associated with histology and size of BOT. Our findings may assist in selection of optimum treatment for BOT patients.

Keywords: Borderline ovarian tumor, Survival, Recurrence, Fertility-preserving surgery, Lymphadenectomy

\section{Background}

Borderline ovarian tumors (BOT) account for $15-20 \%$ of all ovarian tumors [1]. Compared to invasive epithelial ovarian cancers, BOT occurs more commonly at a younger age, during the time of optimum fertility [2]. BOT patients have a good prognosis with 5- and 10-year survival rates of 95 and $92.8 \%$ respectively, and recurrence rates of $5-8 \%[3-5]$. Complete staging is currently the standard surgery treatment for BOT patients. However, the manner and extent of management of these patients remains a subject of debate. Further clinical investigation is needed to achieve clarity concerning which types of fertility-preserving surgery are safer for young patients who desire to retain fertility, whether there is a need to

\footnotetext{
*Correspondence: yuaj@zjcc.org.cn

'Department of Gynecologic Oncology, Zhejiang Cancer Hospital, 1 Banshan East Road, Hangzhou, Zhejiang 310022, China

Full list of author information is available at the end of the article
}

remove retroperitoneal lymph nodes, and whether it is necessary to use adjuvant chemotherapy after surgery.

The objective of the present study was to determine the impact of a number of clinicopathological factors on recurrence and survival of $\mathrm{BOT}$ patients, and to address features related to this disease.

\section{Methods}

BOT patients treated between January 1996 and December 2015 were identified from medical records of our hospital. BOT were confirmed by pathological diagnoses on surgical specimens. Pathological staging was performed according to the criteria of the International Federation of Gynecology and Obstetrics (FIGO) 2014. Due to the retrospective nature of the study, informed consent was waived by the Medical Ethics Committee of our hospital.

Surgical management was based on extent of disease, patient age, and patient's desire to preserve fertility. 
Surgical procedures were classified as radical or fertility-preserving. Removal of both ovaries was classified as radical. The complete staging procedure consisted of total hysterectomy and bilateral accessory resection with or without removal of lymph nodes, resection of the greater omentum below the transverse colon, multiple abdominal biopsies, and peritoneal lavage of exfoliated cells. Fertility-preserving surgery retained the uterus and adnexa at one or both sides. Three types of fertility-preserving surgery were performed: unilateral salpingo-oophorectomy (USO), unilateral salpingo-oophorectomy plus contralateral cystectomy (USO + CC) and bilateral cystectomy (BC). Laparoscopic surgery was selected by patients. All patients that underwent laparoscopic or open surgery had complete staging. Lymphadenectomy was performed based on intraoperative finding of enlarged lymph nodes and/or disseminated foci. Chemotherapy was recommended for all BOT patients with lymph node metastasis, or invasive implant, or at stage III/ IV. Follow-up with patients occurred once every 3 months in the first 2 years and every 6 months thereafter. At the time of follow-up, patients received routine gynecological examination, testing for cancer markers and B ultrasound. If cancer biomarkers and/ or B ultrasound were abnormal, then patients would be examined by CT.

Recurrence was diagnosed by elevated tumor markers plus imaging diagnosis of ovarian or pelvic mass. Progression-free survival (PFS) was defined as the time from the date of primary surgery to detection of first recurrence or the last follow-up. Overall survival (OS) was defined as the time from the date of primary surgery to BOT-specific death or the last follow-up.

\section{Statistical analysis}

All statistical analyses were performed using SAS 9.3 (SAS Institute Inc, Cary, NC). Chi-square was used to examine categorical data. $T$-test was applied to continuous data of two groups. ANOVA with posthoc Tukey test was applied for continuous data over two groups. Univariate and multivariate Cox regression models were used to determine the effect of clinicopathological factors on PFS and OS, and results were presented as hazard ratios (HR). The proportionality assumption was checked by adding a covariate created from an interaction of the predictor and the recurrence time in the model. A collinearity of variables used in the final model was examined by a Chi-square test. The Kaplan-Meier method was also used for analysis of impact of individual variables on PFS. A $P$ value of $<0.05$ was considered to be statistically significant.

\section{Results}

A total of 249 BOT patients were identified. Seventy-one were excluded due to death from other diseases unrelated to BOT (2 cases), or concurrent presence of localized ovarian cancer (46 cases), cervical cancer (12 cases), colorectal cancer (7 cases), and intraperitoneal pseudomyxoma (4 cases). The remaining 178 cases were included in this study and clinicopathological features corresponding to these cases are presented in Table 1. Patient ages ranged from 15 to 87 years with a median age of 43 years. Among them, 90 (50.6\%) patients had preoperative CA125 $\geq 35 \mathrm{U} / \mathrm{ml} ; 50(28.1 \%)$ patients had CA19-9 $\geq 35 \mathrm{U} / \mathrm{ml} ; 28$ (15.8\%) patients had CEA $\geq 3.4 \mathrm{U} /$ $\mathrm{ml}$; and 35 (19.7\%) patients had HE4 $\geq 105 \mathrm{U} / \mathrm{ml}$.

There were 108 patients (61.6\%) who underwent radical surgery. Sixty-eight (38.4\%) patients underwent fertility-preserving surgery, which included 33 (18.6\%) USO, 14 (7.9\%) USO + CC, and 21 (11.9\%) BC. The majority of patients $(93.2 \%)$ were operated on using open surgery. Laparoscopic surgery was performed in 12 patients (6.8\%). Two (1.2\%) of them were converted to open surgery due to intraoperative bleeding caused by injury to iliac blood vessels. Lymphadenectomy was performed in 99 patients (56.2\%) to remove pelvic lymph nodes and in 36 patients (20.2\%) to remove para-aortic lymph nodes. Patients' clinicopathological factors that significantly correlated with lymphadenectomy and positive pelvic lymph node metastasis are presented in Additional file 1: Tables S1 and S2, respectively. Sixty patients (33.7\%) underwent restaging. Ascites of 19 patients $(10.7 \%)$ were identified with positive tumor cells. Rupture occurred in 30 patients (16.9\%) during surgery. A total of 23 patients (12.9\%) underwent adjuvant chemotherapy after initial surgery (Table 1 ). The clinicopathological factors significantly related to chemotherapy are presented in Additional file 1: Table S3.

Pathological information corresponding to BOT is listed in Table 2. The median tumor diameter was $10 \mathrm{~cm}$ (range 2-50 cm). Among these tumors, $84(48.2 \%)$ localized to the left, 63 (35.4\%) localized to the right and 31 (17.4\%) localized bilaterally. Among 115 patients (64.6\%) with stage I disease, 76 patients (42.7\%) were classified as stage Ia, $13(7.3 \%)$ as stage Ib, and $26(14.6 \%)$ as stage Ic. Fourteen patients $(7.8 \%)$ had stage II disease, and 27 patients $(15.2 \%)$ had stage III disease. The histology of BOT included 71 (39.9\%) serous tumor, $80(44.9 \%) \mathrm{mu}-$ cinous tumor and $18(10.1 \%)$ endometrioid tumors. Of the serous BOT cases, 20 (28.2\%) had micropapillary lesions and 11 (15.5\%) had microinvasion lesions. Twenty (25.0\%) mucinous BOT had intraepithelial neoplasia. Of all patients, 8 (4.5\%) had extraovarian invasive implants. The median number of pelvic lymph nodes removed was 9 (range, 1-50) and the median number of harvested para-aortic lymph nodes was 3 (range, 1-6). Fifteen 
Table 1 Demographic and clinical features of BOT patients

Variables
Age (range 15-87
Multiparous
Nulliparous
CA199
CA125
CEA
HE4
USO + CC
Fertility-preserving

Radical surgery

Lymphadenectomy

Restaging

No

Rupture

$$
\text { N/A }
$$

$<35 \mathrm{U} / \mathrm{m}$

$\geq 35 \mathrm{U} / \mathrm{ml}$

N/A

$<35 \mathrm{U} / \mathrm{ml}$

$\geq 35 \mathrm{U} / \mathrm{ml}$

N/A

$<3.4 \mathrm{U} / \mathrm{ml}$

$\geq 3.4 \mathrm{U} / \mathrm{ml}$

N/A

$<105 \mathrm{U} / \mathrm{ml}$

$\geq 105 \mathrm{U} / \mathrm{ml}$

N/A

$N(\%)$
$78(44.1)$
$99(55.9)$

$30(16.9)$

30 (16.9)

$148(83.1)$

117 (65.7)

$50(28.1)$

$3(1.7)$

78 (43.8)

90 (50.6)

10 (5.6)

$138(77.5)$

28 (15.8)

12 (6.7)

131 (73.6)

35 (19.7)

$12(6.7)$

68 (38.4)

33 (18.6)

$14(7.9)$

21 (11.9)

109 (61.6)

$99(56.2 \%)$

77 (43.8\%)

$60(33.7)$

116 (65.2)

$2(1.1)$

$30(16.9)$

66 (36.3)

84 (46.1)

Ascites

$$
\text { N/A }
$$

Positive

107 (60.1)

Negative

52 (29.2)

Surgery approach

N/A

166 (93.2)

$10(5.6)$

Laparoscopic

$2(1.2)$

Chemotherapy

Laparoscopic to open

$23(12.9)$

$157(87.1)$

$32(18.0)$

Recurrence

Yes

$5(2.8)$

$\mathrm{N} / \mathrm{A}$, data not available, USO unilateral salpingo-oophorectom, USO + CC unilateral salpingo-oophorectomy plus contralateral cystectomy, $B C$ bilateral cystectomy

patients (15.2\%) had positive pelvic lymph node metastasis, and six patients (16.7\%) had positive para-aortic lymph node metastasis.

\begin{tabular}{|c|c|c|}
\hline Variables & & N (\%) \\
\hline \multirow[t]{3}{*}{ Location } & Left & $84(48.2)$ \\
\hline & Right & $63(35.4)$ \\
\hline & Bilateral & $31(17.4)$ \\
\hline \multirow[t]{3}{*}{ Diameter } & $\geq 10 \mathrm{~cm}$ & $78(43.8)$ \\
\hline & $<10 \mathrm{~cm}$ & $74(41.6)$ \\
\hline & N/A & $26(14.6)$ \\
\hline \multirow[t]{4}{*}{ Histology } & Serous & $71(39.9)$ \\
\hline & Mucinous & $80(44.9)$ \\
\hline & Endometrioid & $18(10.1)$ \\
\hline & N/A & $9(5.1)$ \\
\hline \multirow[t]{6}{*}{ Stage } & la & $76(42.7)$ \\
\hline & $\mathrm{lb}$ & $13(7.3)$ \\
\hline & Ic & $26(14.6)$ \\
\hline & $\|$ & $14(7.8)$ \\
\hline & III & $27(15.2)$ \\
\hline & N/A & $22(12.4)$ \\
\hline Micropapillary $^{a}$ & Yes & $20(28.2)$ \\
\hline Microinvasion $^{\mathrm{a}}$ & Yes & $11(15.5)$ \\
\hline Intraepithelial neoplasia ${ }^{\text {b }}$ & Yes & $20(25.0)$ \\
\hline \multirow[t]{2}{*}{ Pelvic lymph node } & Positive & $15(15.2)$ \\
\hline & Negative & $84(84.8)$ \\
\hline \multirow[t]{2}{*}{ Para-aortic lymph node } & Positive & $6(16.7)$ \\
\hline & Negative & $30(83.3)$ \\
\hline Invasive implants & Yes & $8(4.5)$ \\
\hline \multirow[t]{2}{*}{ Residue } & & $2(1.1)$ \\
\hline & & $176(98.9)$ \\
\hline
\end{tabular}

Table 2 Pathological features of BOT

N/A data not available; ${ }^{\mathrm{a}} \%$ of serous tumors; ${ }^{\mathrm{b}} \%$ of mucinous tumor

The median follow-up time was 37 months (range, 11-180 months). At the time of last follow-up, $32 \mathrm{pa}$ tients $(18.0 \%)$ had recurrences and $5(2.8 \%)$ of them died of the disease after surgery; two patients $(1.1 \%)$ were lost to follow-up. Detailed information corresponding to recurrence sites for these patients is presented in Additional file 1: Table S4. These recurrent patients were treated by cytoreductive or staging surgery with or without chemotherapy, or fertility preservation staging surgery.

Univariate Cox regression analysis showed that these variables were significantly associated with PFS: tumor diameter $(P=0.0076)$, mucinous histology $(P=0.0375)$, lymphadenectomy $(P=0.0328)$, positive pelvic lymph node metastasis $(P=0.0246)$, para-aortic lymph node metastasis $(P=0.0137)$, tumor stages $(P=0.0295)$, invasive implant $(P=0.0038)$, fertility preserving surgery $(P=$ 0.0007 for $\mathrm{BC}$, and $P=0.0003$ for $\mathrm{USO}+\mathrm{CC}$ ) and adjuvant chemotherapy $(P=0.0164)$. Survival curves by lymphadenectomy and invasive implants are displayed in 
Fig. 1. The recurrence outcomes categorized with above clinicopathological variables are presented in Additional file 1: Table S5.

A multivariate Cox regression model was built after controlling for tumor histology and stages. Our results showed a significant negative correlation between fertility-preserving surgery and invasive implants to PFS ( $P=0.0223$ for $\mathrm{BC}$ and $P=0.0030$ for invasive implants). Lymphadenectomy was significantly associated with improved PFS $(P=0.0129)$ (Table 3$)$.

Univariate Cox regression analyses were performed to determine effects of clinicopathological variables on OS. No factors were found to be significantly associated with OS in both models.

The relationship between histology of BOT and blood cancer markers CA19-9, CA125, CEA, and HE4 was determined (Table 4). Our results showed that patients with serous BOT were more likely to have abnormal CA125 $(P=0.025)$, and patients with mucinous BOT were more likely to have abnormal CEA levels $(P=0.0005)$.

The relationship between tumor sizes and blood cancer markers was also analyzed. Our results showed that BOT patients with abnormal preoperative CA199, CEA and HE4 levels had significantly larger tumor sizes $(P=0.0048, P<0.0001$, and $P=0.0411$, respectively) (Table 5).

\section{Discussion}

Despite a good prognosis, even with recurrence, there has been little consensus concerning optimal management of BOT cases and a lack of clarity on best strategies. Identification of clinicopathological variables predicting recurrence and survival may assist in selection of optimum treatments for BOT patients. This retrospective study showed that certain types of fertilitypreserving surgery, lymphadenectomy and invasive implants were associated with PFS of BOT patients. Due to the limited number of deaths, no factors related to OS were identified.
BOT often occurs in younger patients during childbearing years. Fertility-preserving surgery is an important option for many of these women. Previous studies have failed to reveal an impact on OS of fertilitypreserving surgery [6]. The effect of fertility-preserving surgery on recurrence remains inconclusive. Several studies report no impact of fertility-preserving surgery on recurrence [7-9], whereas others report an association with worse PFS [6, 10-14]. Fertility-preserving surgery can be performed in different ways and this can impact outcomes. In comparison to salpingo-oophorectomy, cystectomy retains more normal ovarian tissue and increases rates of pregnancy success [15]. On the other hand, cystectomy may increase the risk of recurrence. Our results showed that PFS was worse for patients that underwent $\mathrm{BC}$ compared to patients that underwent radical surgery. There was no significant difference in PFS between the other methods of fertility-preserving surgery (USO and $\mathrm{USO}+\mathrm{CC}$ ) and radical surgery, or among the three styles of fertility-preserving surgery. This is corroborated by findings in other studies: Chen et al. found that the choice of surgical methods used to preserve fertility had significant impact on recurrence and subsequent pregnancy [15]; the same is reported in other studies [16, 17]. Taken together, these results suggest that the types of fertilitypreserving surgery have different impacts on oncologic and pregnancy outcomes of BOT patients.

A dilemma encountered in treating BOT patients occurs around the question of whether or not to remove the retroperitoneal lymph nodes during surgery. Shih et al. reported that approximately half of 266 patients underwent lymphadenectomy and that lymphadenectomy was not significantly associated with PFS in their study [9]. Other studies also report that lymphadenectomy did not improve PFS or OS for BOT patients [1822]. In our study, a total of 99 patients (56.2\%) underwent lymphadenectomy and this was significantly associated with improved PFS. This finding is consistent with the results of a previous study [23]. It is also noted that $8.4 \%$ of these patients had pelvic lymph node metastasis
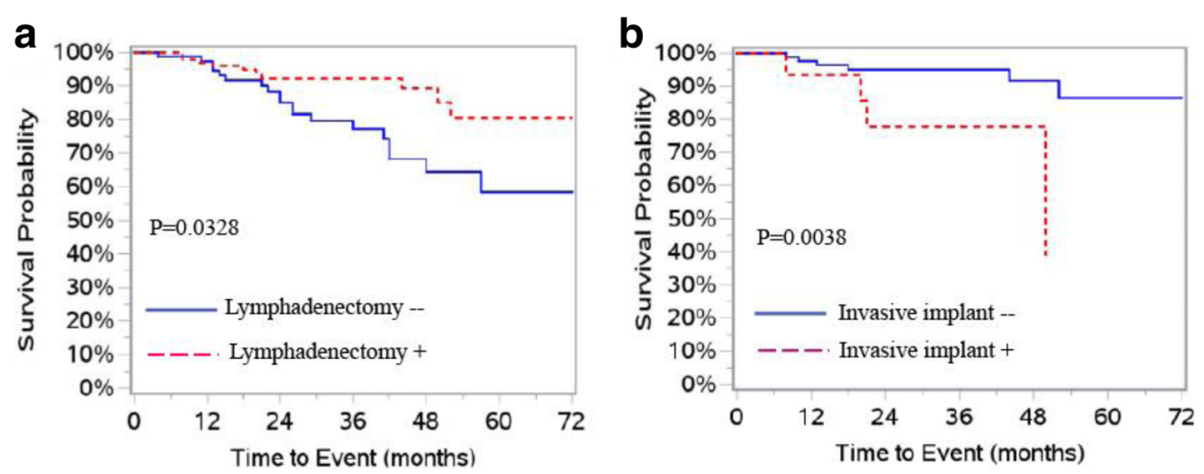

Fig. 1 PFS curves in patients with BOT. a PFS by lymphadenectomy. b PFS by invasive implants 
Table 3 Univariate and multivariate analysis of progression-free survival

\begin{tabular}{|c|c|c|c|c|c|c|c|}
\hline \multirow[t]{2}{*}{ Variables } & & \multicolumn{2}{|c|}{ Univariate } & \multirow[t]{2}{*}{$P$} & \multicolumn{2}{|c|}{ Multivariate $^{a}$} & \multirow[t]{2}{*}{$P$} \\
\hline & & $\mathrm{HR}$ & $95 \% \mathrm{Cl}$ & & $\mathrm{HR}$ & $95 \% \mathrm{Cl}$ & \\
\hline Multiparous & Yes & 0.32 & $0.15-0.67$ & 0.024 & & & \\
\hline Nulliparous & No & 1 & & & & & \\
\hline \multirow[t]{2}{*}{ Diameter } & $\geq 10$ & 0.26 & $0.09-0.70$ & 0.0076 & & & \\
\hline & $<10$ & 1 & & & & & \\
\hline \multirow[t]{3}{*}{ Histology } & Serous & 1 & & & & & \\
\hline & Mucinous & 0.41 & $0.18-0.95$ & 0.0375 & & & \\
\hline & Endometrioid & 0.64 & $0.19-2.19$ & 0.4808 & & & \\
\hline \multirow[t]{2}{*}{ Micropapillary } & Yes & 3.88 & $1.76-8.52$ & 0.0008 & & & \\
\hline & No & 1 & & & & & \\
\hline \multirow[t]{2}{*}{ Stage } & $\|\&\|$ & 2.55 & $1.10-5.91$ & 0.0295 & & & \\
\hline & । & 1 & & & & & \\
\hline \multicolumn{8}{|l|}{ Fertility preserving surgery } \\
\hline USO & & 1.6 & $0.59-4.33$ & 0.3553 & 1.26 & $0.37-4.08$ & 0.7395 \\
\hline USO + CC & & 5.74 & $2.10-15.67$ & 0.0007 & 2.72 & $0.65-11.38$ & 0.1719 \\
\hline $\mathrm{BC}$ & & 5.89 & $2.25-14.42$ & 0.0003 & 3.95 & $1.22-12.85$ & 0.0223 \\
\hline Radical surgery & & 1 & & & & & \\
\hline \multirow[t]{2}{*}{ Invasive implant } & Yes & 4.87 & $1.67-14.20$ & 0.0038 & 10.38 & $2.21-48.69$ & 0.0030 \\
\hline & No & 1 & & & & & \\
\hline \multirow[t]{2}{*}{ Lymphadenectomy } & Yes & 0.44 & $0.21-0.94$ & 0.0328 & 0.26 & $0.09-0.75$ & 0.0129 \\
\hline & No & 1 & & & & & \\
\hline \multirow[t]{2}{*}{ Pelvic lymph node metastasis } & Yes & 4.34 & $1.21-15.67$ & 0.0246 & & & \\
\hline & No & 1 & & & & & \\
\hline \multirow[t]{2}{*}{ Para-aortic lymph node metastasis } & Yes & 17.34 & $1.80-167.50$ & 0.0137 & & & \\
\hline & No & 1 & & & & & \\
\hline \multirow[t]{2}{*}{ Chemotherapy } & Yes & 2.72 & $1.20-6.19$ & 0.0164 & & & \\
\hline & No & & & & & & \\
\hline \multirow[t]{2}{*}{ Restaging } & Yes & 9.8 & $3.96-23.78$ & $<0.0001$ & & & \\
\hline & No & & & & & & \\
\hline
\end{tabular}

USO unilateral salpingo-oophorectom, USO + CC unilateral salpingo-oophorectomy plus contralateral cystectomy, $B C$ bilateral cystectomy ${ }^{a}$ Multivariate model was built after controlling for tumor histology and stage

Table 4 Relationship between blood cancer markers and histology of BOT

\begin{tabular}{|c|c|c|c|c|c|}
\hline \multirow[t]{2}{*}{ Markers } & & \multicolumn{3}{|l|}{ Histology } & \multirow[t]{2}{*}{$P^{*}$} \\
\hline & & Serous & Mucinous & Endometrioid & \\
\hline \multirow[t]{2}{*}{ CA199 } & $<35 \mathrm{U} / \mathrm{ml}$ & $52(46.4)$ & $47(42.0)$ & $13(11.6)$ & \multirow[t]{2}{*}{0.2959} \\
\hline & $\geq 35 \mathrm{U} / \mathrm{ml}$ & $17(24.7)$ & $27(55.1)$ & $5(10.2)$ & \\
\hline \multirow[t]{2}{*}{ CA125 } & $<35 \mathrm{U} / \mathrm{ml}$ & $24(32.0)$ & $43(57.3)$ & $8(10.7)$ & \multirow[t]{2}{*}{0.025} \\
\hline & $\geq 35 \mathrm{U} / \mathrm{ml}$ & $45(51.7)$ & $32(36.8)$ & $10(11.5)$ & \\
\hline \multirow[t]{2}{*}{ CEA } & $<3.4 \mathrm{U} / \mathrm{ml}$ & 66 (49.6) & $52(39.1)$ & $15(11.3)$ & \multirow[t]{2}{*}{0.0005} \\
\hline & $\geq 3.4 \mathrm{U} / \mathrm{ml}$ & $3(11.1)$ & $21(77.8)$ & $3(11.1)$ & \\
\hline \multirow[t]{2}{*}{ HE4 } & $<105 \mathrm{U} / \mathrm{ml}$ & $52(41.6)$ & $63(50.4)$ & $10(8.0)$ & \multirow[t]{2}{*}{0.0696} \\
\hline & $\geq 105 \mathrm{U} / \mathrm{ml}$ & $16(45.7)$ & $12(34.3)$ & $7(20.0)$ & \\
\hline
\end{tabular}

${ }^{*}$ Results of $x^{2}$-test
Table 5 Tumor sizes based on categorized blood cancer markers

\begin{tabular}{lllcl}
\hline & & Number & Tumor size $(\mathrm{cm})$ & $P^{*}$ \\
\hline CA199 & $<35 \mathrm{U} / \mathrm{ml}$ & 99 & $10.6 \pm 6.3$ & 0.0048 \\
& $\geq 35 \mathrm{U} / \mathrm{ml}$ & 42 & $14.2 \pm 8.1$ & \\
CA125 & $<35 \mathrm{U} / \mathrm{ml}$ & 64 & $11.1 \pm 6.7$ & 0.4269 \\
& $\geq 35 \mathrm{U} / \mathrm{ml}$ & 78 & $12.1 \pm 7.3$ & \\
CEA & $<3.4 \mathrm{U} / \mathrm{ml}$ & 118 & $10.5 \pm 5.7$ & $<0.0001$ \\
& $\geq 3.4 \mathrm{U} / \mathrm{ml}$ & 22 & $17.4 \pm 9.8$ & \\
HE4 & $<105 \mathrm{U} / \mathrm{ml}$ & 77 & $11.0 \pm 6.6$ & 0.0411 \\
& $\geq 105 \mathrm{U} / \mathrm{ml}$ & 33 & $13.8 \pm 8.1$ &
\end{tabular}


and $16.7 \%$ of patients had para-aortic lymph node metastasis. Ureyen et al. found that positive lymph node metastasis was significantly associated with worse PFS in patients with serous BOT [24]. It is plausible that lymphadenectomy may improve PFS through removal of lymph node metastasis.

Several reports indicate that invasive peritoneal implants are associated with a poor prognosis [14, 25-30]. Consistent with these finding, our study showed that presence of invasive implants was significantly associated with worse PFS in BOT patients. These data suggest that BOT patients with invasive implants may require more aggressive treatments. Serous BOT with invasive implant is considered to be low-grade serous adenocarcinoma and is associated with a significantly worse prognosis [31]. However, this study included only eight BOT patients $(4.4 \%)$ that had invasive implants. Our data did not reveal a difference in PFS among patients with BOT of different histological types. Conversely, invasive implants may not be identified as a prognostic factor due to inaccuracy of implant diagnosis made for various reasons [32].

Adjuvant chemotherapy has been shown to significantly increase toxicity without therapeutic benefits in BOT patients with stage I disease [33]. Other studies report no benefits of adjuvant chemotherapy regardless of stage or tumor histology [34, 35]. A meta-analysis revealed no significant effect of adjuvant chemotherapy on survival in BOT patients with invasive implants [36]. Findings reported here are in agreement with these reports: our multivariate model showed adjuvant chemotherapy is not a factor that is significantly associated with PFS.

It has been reported that serous BOT is more common in Western countries and mucinous histology is more common in Asian countries [37]. More cases of mucinous vs serous BOT were observed in the Chinese patients in our study (44.9\% vs $39.9 \%$ ). In addition, mucinous tumors $(15.2 \pm 7.7 \mathrm{~cm})$ were significantly larger than both serous $(8.3 \pm 3.9 \mathrm{~cm})$ and endometroid tumors $(8.6 \pm 4.8 \mathrm{~cm})$ (Both $P<0.01)$, as reported previously $[38,39]$. However, multivariate analysis performed in this study revealed no significant difference in PFS in patients with serous BOT compared to those with mucinous BOT.

Higher levels of the serum tumor markers CA125 and CA19-9 have been shown to be associated with larger tumor size. The elevation of serum CA125 may suggest serous tumors [40], while high levels of serum CA19-9 and CEA may indicate mucinous BOTs [41]. In our study, we also observed that sizes of BOT were significantly associated with higher levels of CA19-9, CEA and HE4. Significantly more patients with serous BOT had abnormal CA125 $(\geq 35 \mathrm{U} / \mathrm{ml})$, and significantly more patients with mucinous BOT had abnormal CEA levels $(\geq 3.4 \mathrm{U} / \mathrm{ml})$. Although previous studies have suggested that preoperative blood CA125 levels may serve as a prognostic marker for BOT patients $[9,42]$, our study did not reveal an association between PFS and preoperative blood levels of CA125, CA19-9, CEA or HE4.

The retrospective nature of this study, the relatively small number of patients, and the short follow-up time may present limitations to the application of findings reported here. A small number of patients (5) represented in this study died of the disease. Fertility outcomes of BOT patients that underwent fertility-preserving surgery is not available.

\section{Conclusions}

Our study reveals that certain types of fertilitypreserving surgery, lymphadenectomy, and invasive implant are related to PFS in BOT patients. Blood cancer markers may be associated with histology and size of BOT. These findings may assist in selection of optimum management of BOT.

\section{Additional file}

Additional file 1: Table S1. Clinicopathological features of patients with lymphadenectomy. Table S2. Clinicopathological features of patients with lymph node metastasis. Table S3. Clinicopathological features of patients with chemotherapy. Table S4. Information of recurrence sites. Table S5. Recurrence outcomes in patients based on clinicopathological classifications. (DOC $92 \mathrm{~kb}$ )

\section{Abbreviations}

BC: Bilateral cystectomy; BOTs: Borderline ovarian tumors; FIGO: International Federation of Gynecology and Obstetrics; N/A: Not applicable; OS: Overall survival; PFS: Progressive free survival; USO: Unilateral salpingooophorectomy; USO + CC: Unilateral salpingo-oophorectomy plus contralateral cystectomy

\section{Acknowledgements}

We thank Dr. Rosemary Hage for her help in reviewing the manuscript.

\section{Funding}

This research is supported by Zhejiang Natural Science Foundation (LY14H160010).

\section{Availability of data and materials}

All data generated or analyzed during this study are included in this published article and its Additional file.

\section{Authors' contributions}

$X C$ and $A Y$ conceived of the concept. XC, AY, CF, TZ and PZ participated in data collection and interpretation of results. XC, AY and SW analyzed data and wrote the manuscript. All authors read and approved the final manuscript.

\section{Competing interests}

The authors declare that they have no competing interests.

Consent for publication

Not applicable.

Ethics approval and consent to participate

Due to the retrospective nature of the study, informed consent was waived by the Medical Ethics Committee of Zhejiang Cancer Hospital. 


\section{Publisher's Note}

Springer Nature remains neutral with regard to jurisdictional claims in published maps and institutional affiliations.

\section{Author details}

'Department of Gynecologic Oncology, Zhejiang Cancer Hospital, 1 Banshan East Road, Hangzhou, Zhejiang 310022, China. ${ }^{2}$ Department of Cancer Biology, Wake Forest School of Medicine, Winston Salem, NC 27157, USA.

\section{Received: 6 February 2017 Accepted: 21 March 2017}

\section{Published online: 04 April 2017}

\section{References}

1. Skirnisdottir I, Garmo H, Wilander E, Holmberg L. Borderline ovarian tumors in Sweden 1960-2005: trends in incidence and age at diagnosis compared to ovarian cancer. Int J Cancer. 2008;123(8):1897-901.

2. Akeson M, Zetterqvist BM, Dahllof K, Jakobsen AM, Brannstrom M, Horvath G. Population-based cohort follow-up study of all patients operated for borderline ovarian tumor in western Sweden during an 11-year period. Int $J$ Gynecol Cancer. 2008;18(3):453-9.

3. Benedet JL, Bender H, Jones 3rd H, Ngan HY, Pecorelli S. FIGO staging classifications and clinical practice guidelines in the management of gynecologic cancers. FIGO Committee on Gynecologic Oncology. Int J Gynaecol Obstet. 2000;70(2):209-62.

4. Morice P. Borderline tumours of the ovary and fertility. Eur J Cancer. 2006; 42(2):149-58.

5. Tinelli R, Tinelli A, Tinelli FG, Cicinelli E, Malvasi A. Conservative surgery for borderline ovarian tumors: a review. Gynecol Oncol. 2006;100(1):185-91.

6. Trillsch F, Mahner S, Woelber L, Vettorazzi E, Reuss A, Ewald-Riegler N, de Gregorio N, Fotopoulou C, Schmalfeldt B, Burges A, et al. Age-dependent differences in borderline ovarian tumours (BOT) regarding clinical characteristics and outcome: results from a sub-analysis of the Arbeitsgemeinschaft Gynaekologische Onkologie (AGO) ROBOT study. Ann Oncol. 2014;25(7):1320-7.

7. Morris RT, Gershenson DM, Silva EG, Follen M, Morris M, Wharton JT. Outcome and reproductive function after conservative surgery for borderline ovarian tumors. Obstet Gynecol. 2000;95(4):541-7.

8. Tazelaar HD, Bostwick DG, Ballon SC, Hendrickson MR, Kempson RL. Conservative treatment of borderline ovarian tumors. Obstet Gynecol. 1985;66(3):417-22.

9. Shih KK, Zhou Q, Huh J, Morgan JC, lasonos A, Aghajanian C, Chi DS, Barakat RR, Abu-Rustum NR. Risk factors for recurrence of ovarian borderline tumors. Gynecol Oncol. 2011;120(3):480-4.

10. Zanetta G, Rota S, Chiari S, Bonazzi C, Bratina G, Mangioni C. Behavior of borderline tumors with particular interest to persistence, recurrence, and progression to invasive carcinoma: a prospective study. J Clin Oncol. 2001:19(10):2658-64.

11. Kane A, Uzan C, Rey A, Gouy S, Camatte S, Pautier P, Lhomme C, HaieMeder C, Duvillard P, Morice P. Prognostic factors in patients with ovarian serous low malignant potential (borderline) tumors with peritoneal implants. Oncologist. 2009;14(6):591-600.

12. Uzan C, Kane A, Rey A, Gouy S, Duvillard P, Morice P. Outcomes after conservative treatment of advanced-stage serous borderline tumors of the ovary. Ann Oncol. 2010;21(1):55-60

13. Fauvet R, Boccara J, Dufournet C, David-Montefiore E, Poncelet C, Darai E. Restaging surgery for women with borderline ovarian tumors: results of a French multicenter study. Cancer. 2004;100(6):1145-51.

14. Obermair A, Tang A, Kondalsamy-Chennakesavan S, Ngan H, Zusterzeel P, Quinn M, Carter J, Leung Y, Janda M. Nomogram to predict the probability of relapse in patients diagnosed with borderline ovarian tumors. International journal of gynecological cancer : official journal of the International Gynecological Cancer Society. 2013;23(2):264-7.

15. Chen RF, Li J, Zhu TT, Yu HL, Lu X. Fertility-sparing surgery for young patients with borderline ovarian tumors (BOTs): single institution experience. J Ovarian Res. 2016;9:16.

16. Palomba S, Zupi E, Russo T, Falbo A, Del Negro S, Manguso F, Marconi D, Tolino A, Zullo F. Comparison of two fertility-sparing approaches for bilateral borderline ovarian tumours: a randomized controlled study. Hum Reprod. 2007;22(2):578-85.

17. Alvarez RM, Vazquez-Vicente D. Fertility sparing treatment in borderline ovarian tumours. Ecancermedicalscience. 2015;9:507.

18. Snider DD, Stuart GC, Nation JG, Robertson DI. Evaluation of surgical staging in stage I low malignant potential ovarian tumors. Gynecol Oncol. 1991; 40(2):129-32.
19. Winter 3rd WE, Kucera PR, Rodgers W, McBroom JW, Olsen C, Maxwell GL. Surgical staging in patients with ovarian tumors of low malignant potential. Obstet Gynecol. 2002;100(4):671-6.

20. Rao GG, Skinner E, Gehrig PA, Duska LR, Coleman RL, Schorge JO. Surgical staging of ovarian low malignant potential tumors. Obstet Gynecol. 2004; 104(2):261-6.

21. Camatte $S$, Morice P, Thoury A, Fourchotte V, Pautier P, Lhomme C, Duvillard P, Castaigne D. Impact of surgical staging in patients with macroscopic "stage I" ovarian borderline tumours: analysis of a continuous series of 101 cases. Eur J Cancer. 2004;40(12):1842-9.

22. Matsuo K, Machida H, Takiuchi T, Grubbs BH, Roman LD, Sood AK, Gershenson DM. Role of hysterectomy and lymphadenectomy in the management of early-stage borderline ovarian tumors. Gynecol Oncol. 2017;144(3):496-502

23. McKenney JK, Balzer BL, Longacre TA. Lymph node involvement in ovarian serous tumors of low malignant potential (borderline tumors): pathology, prognosis, and proposed classification. Am J Surg Pathol. 2006;30(5):614-24.

24. Ureyen I, Karalok A, Tasci T, Turkmen O, Boran N, Tulunay G, Turan T. The Factors Predicting Recurrence in Patients With Serous Borderline Ovarian Tumor. International journal of gynecological cancer : official journal of the International Gynecological Cancer Society. 2016;26(1):66-72.

25. Prat J, De Nictolis M. Serous borderline tumors of the ovary: a long-term follow-up study of 137 cases, including 18 with a micropapillary pattern and 20 with microinvasion. Am J Surg Pathol. 2002;26(9):1111-28.

26. Boran N, Cil AP, Tulunay G, Ozturkoglu E, Koc S, Bulbul D, Kose MF. Fertility and recurrence results of conservative surgery for borderline ovarian tumors. Gynecol Oncol. 2005;97(3):845-51.

27. Park JY, Kim DY, Kim JH, Kim YM, Kim KR, Kim YT, Nam JH. Micropapillary pattern in serous borderline ovarian tumors: does it matter? Gynecol Oncol. 2011;123(3):511-6.

28. Cusido M, Balaguero L, Hernandez G, Falcon O, Rodriguez-Escudero FJ, Vargas JA, Vidart JA, Zamora L, Monera M, Alonso A, et al. Results of the national survey of borderline ovarian tumors in Spain. Gynecol Oncol. 2007: 104(3):617-22.

29. Morice P, Camatte S, Rey A, Atallah D, Lhomme C, Pautier P, Pomel C, Cote JF, Haie-Meder C, Duvillard P, et al. Prognostic factors for patients with advanced stage serous borderline tumours of the ovary. Ann Oncol. 2003; 14(4):592-8.

30. Seidman JD, Kurman RJ. Ovarian serous borderline tumors: a critical review of the literature with emphasis on prognostic indicators. Hum Pathol. 2000; 31(5):539-57.

31. Bell DA, Longacre TA, Prat J, Kohn EC, Soslow RA, Ellenson LH, Malpica A, Stoler MH, Kurman RJ. Serous borderline (low malignant potential, atypical proliferative) ovarian tumors: workshop perspectives. Hum Pathol. 2004; 35(8):934-48.

32. Fischerova D, Zikan M, Dundr P, Cibula D. Diagnosis, treatment, and followup of borderline ovarian tumors. Oncologist. 2012;17(12):1515-33.

33. Trope C, Kaern J, Vergote IB, Kristensen G, Abeler V. Are borderline tumors of the ovary overtreated both surgically and systemically? A review of four prospective randomized trials including 253 patients with borderline tumors. Gynecol Oncol. 1993;51(2):236-43.

34. Faluyi O, Mackean M, Gourley C, Bryant A, Dickinson HO. Interventions for the treatment of borderline ovarian tumours. Cochrane Database Syst Rev. 2010:9:CD007696.

35. Sutton GP, Bundy BN, Omura GA, Yordan EL, Beecham JB, Bonfiglio T. Stage III ovarian tumors of low malignant potential treated with cisplatin combination therapy (a Gynecologic Oncology Group study). Gynecol Oncol. 1991;41(3):230-3.

36. Vasconcelos I, Olschewski J, Braicu I, Sehouli J. A meta-analysis on the impact of platinum-based adjuvant treatment on the outcome of borderline ovarian tumors with invasive implants. Oncologist. 2015;20(2):151-8.

37. Song T, Lee YY, Choi CH, Kim TJ, Lee JW, Bae DS, Kim BG. Histologic distribution of borderline ovarian tumors worldwide: a systematic review. J Gynecol Oncol. 2013;24(1):44-51.

38. Kurman R, Shih le M. Pathogenesis of ovarian cancer: lessons from morphology and molecular biology and their clinical implications. Int J Gynecol Pathol. 2008: 27(2):151-60.

39. Messalli EM, Grauso F, Balbi G, Napolitano A, Seguino E, Torella M. Borderline ovarian tumors: features and controversial aspects. Eur J Obstet Gynecol Reprod Biol. 2013:167(1):86-9.

40. Gotlieb WH, Soriano D, Achiron R, Zalel Y, Davidson B, Kopolovic J, Novikov 1. Ben-Baruch G. CA 125 measurement and ultrasonography in borderline tumors of the ovary. Am J Obstet Gynecol. 2000;183(3):541-6. 
41. Ayhan A, Guven S, Guven ES, Kucukali T. Is there a correlation between tumor marker panel and tumor size and histopathology in well staged patients with borderline ovarian tumors? Acta Obstet Gynecol Scand. 2007; 86(4):484-90.

42. Tang A, Kondalsamy-Chennakesavan S, Ngan H, Zusterzeel P, Quinn M, Carter J, Leung Y, Obermair A. Prognostic value of elevated preoperative serum CA125 in ovarian tumors of low malignant potential: a multinational collaborative study (ANZGOG0801). Gynecol Oncol. 2012;126(1):36-40.

Submit your next manuscript to BioMed Central and we will help you at every step:

- We accept pre-submission inquiries

- Our selector tool helps you to find the most relevant journal

- We provide round the clock customer support

- Convenient online submission

- Thorough peer review

- Inclusion in PubMed and all major indexing services

- Maximum visibility for your research

Submit your manuscript at www.biomedcentral.com/submit 